\title{
Lack of tolerable treatment options for patients with schizophrenia
}

\author{
This article was published in the following Dove Press journal: \\ Neuropsychiatric Disease and Treatment \\ 16 December 2015 \\ Number of times this article has been viewed
}

\author{
Leslie Citrome' \\ Anna Eramo ${ }^{2}$ \\ Clement Francois ${ }^{2}$ \\ Ruth Duffy ${ }^{3}$ \\ Susan N Legacy ${ }^{3}$ \\ Steve J Offord ${ }^{3}$ \\ Holly B Krasa ${ }^{3}$ \\ Stephen S Johnston ${ }^{4}$ \\ Alice Guiraud-Diawara ${ }^{5}$ \\ Siddhesh A Kamat ${ }^{3}$ \\ Patricia Rohman ${ }^{3}$ \\ 'Department of Psychiatry and \\ Behavioral Sciences, New York \\ Medical College, Valhalla, NY, \\ ${ }^{2}$ Lundbeck, Deerfield, IL, ${ }^{3}$ Otsuka \\ America Pharmaceuticals, Princeton, \\ NJ, ${ }^{4}$ Truven Health Analytics, \\ Bethesda, MD, USA; ${ }^{5}$ Lundbeck \\ SAS, Issy-les-Moulineaux, France
}

Correspondence: Leslie Citrome

I I Medical Park Drive, Suite 106,

Pomona, NY 10970, USA

Tel + I 845362208 I

Fax +l 8453628745

Email citrome@cnsconsultant.com
Purpose: Atypical antipsychotics (AAs), an effective treatment for schizophrenia, have a range of pharmacologic properties leading to differences in tolerability as well as heterogeneity in treatment response. Individual patient characteristics must be considered when making treatment choices, especially from an adverse event (AE) or tolerability perspective. Despite the availability of numerous AAs, after appraising patient characteristics at the time of treatment selection, physicians may quickly run out of tolerable treatment options.

Patients and methods: AE risk factors, defined as having either a prior history of an $\mathrm{AE}$ or a risk factor for that $\mathrm{AE}$, were determined for Medicaid-insured and Commercially insured patients using database analysis. Patients receiving AA treatment between January 1, 2010 and December 31, 2012 defined the index date of first observed AA prescription during this period. Nine AAs were evaluated for association with AE risk factors as informed by drug prescribing information from the different manufacturers and published meta-analyses. The proportion of patients with pre-index AE risk factors prescribed an AA associated with that risk factor was then determined.

Results: A high proportion of patients $(>80 \%)$ were prescribed an AA associated with extrapyramidal symptoms or akathisia despite experiencing extrapyramidal symptoms or akathisia prior to AA treatment initiation. Similar trends were observed among patients with diabetes $(>60 \%)$ and obesity $(>40 \%)$. From the nine treatment options available, the number of optimal choices for individual patient segments were limited based on their prior history, including those with cardiometabolic and cardiovascular comorbidities (four); experiencing prolactin elevation-related problems (seven); needing to avoid excessive sedation (four); or at risk of extrapyramidal symptoms or akathisia (two). Options were then further restricted among patients in more than one segment when multiple pre-index AE risk factors were combined.

Conclusion: When combining patient risk profile with antipsychotic AE profile, physicians may quickly run out of tolerable treatment options for individual patients, despite the availability of many AAs, suggesting a need for additional treatment options with better tolerability and without compromising efficacy.

Keywords: schizophrenia, atypical antipsychotics, tolerability, comorbidities, treatment

\section{Background}

Schizophrenia is a chronic and disabling psychiatric disorder affecting an estimated $1.1 \%$ of adults (2.6 million) in the US, with onset commonly occurring in early adulthood. ${ }^{1,2}$ Schizophrenia is also associated with significant medical comorbidities and excess mortality; compared with healthy controls, patients with schizophrenia have a nearly twofold increase in mortality rate. ${ }^{3}$ Antipsychotic therapy remains the mainstay of schizophrenia treatment, with patients requiring lifelong use of antipsychotic medication to manage their disease. ${ }^{4}$ Antipsychotics are beneficial in controlling many of the symptoms of schizophrenia, but are also associated with side effects. ${ }^{5,6}$ While 
atypical antipsychotics (AAs) are associated with a lower risk of producing extrapyramidal symptoms (EPS), many are associated with a greater risk of metabolic side effects. ${ }^{6,7}$

Although there are several antipsychotics available in the US, these treatments may not be interchangeable given their varying efficacy and tolerability profiles. This is an important consideration in the design of pharmacy formularies to provide physicians with sufficient treatment options for their patients. Further, health plan formularies carrying only select generic AAs may further exacerbate the problem for specific patient segments with comorbidities, ${ }^{8-10}$ and physicians may quickly exhaust available AA treatment options for their patients due to the combined effect of heterogeneity of patient type and heterogeneity of AA treatment response. This is particularly the case for patients with schizophrenia, where much attention has been placed on the somatic comorbidities commonly encountered in patients with schizophrenia, including diabetes, weight gain, cardiovascular disease (CVD), orthostatic hypotension, and QTc prolongation. This attention has led to a number of guidelines on how to assess and manage such issues. ${ }^{11-13}$ In particular, baseline cardiometabolic risk appears higher for patients with schizophrenia compared with the general population and there remain concerns that some antipsychotic medications can elevate that risk. ${ }^{14}$

In addition, prescribers rely on access to a diverse choice of AAs due to the range of pharmacologic properties which may confer significant clinical differences among the available agents. ${ }^{6}$ A recent multiple-treatment meta-analysis study challenges the impression that the efficacy of all antipsychotics drugs is similar and also indicates that AAs have robust difference in their tolerability profiles, which may lead to tolerability-related treatment discontinuation. ${ }^{15}$ The prescribing physician also needs to be aware of the significant comorbidities in the schizophrenic patient population. ${ }^{16,17}$ Reports on the Schizophrenia Patient Outcomes Research Team treatment recommendations and the Mount Sinai Conference Safety Monitoring recommendations suggest that patients in community mental health centers are not adequately monitored by their health care providers for medical comorbidities, including metabolic diseases. ${ }^{18}$ Differences between AAs in terms of efficacy and tolerability call for an individualized treatment approach. Although treatment guidelines exist, including the US and International guidelines (American Psychiatric Association ${ }^{12}$ and World Federation of Societies of Biological Psychiatry ${ }^{19}$ ), it is still not possible to know in advance which antipsychotics are most efficacious for any individual patient; heterogeneity of treatment response results in patients commonly being sequentially treated with different antipsychotic medications in order to find the optimum choice of medication for the individual patient..$^{20,21}$ These factors illustrate the importance of the use of appropriate tolerable treatments for patients and the need for availability of such treatments from a formulary access perspective.

The current study examines whether there is a need for additional tolerable and efficacious treatment options for individual patients that can thus provide a personalized therapeutic approach. This study determines the proportion of patients with schizophrenia that have unmet needs in terms of availability of tolerable treatments. Specifically, the study objectives were to: 1) determine adverse event (AE) risk factors for patients with schizophrenia, defined as having either a prior history of an $\mathrm{AE}$ or a risk factor for that $\mathrm{AE}$; 2) evaluate AAs for their association with AE risk factors using previously analyzed drug prescribing information and published meta-analyses and then; 3 ) determine the proportion of patients with $\mathrm{AE}$ risk factors during the pre-index period and who were prescribed an AA associated with those same risk factors; and finally 4) present a list of appropriate tolerable treatment options for various schizophrenia patient segments with pre-existing AE risk factors.

\section{Methods}

\section{Study design and data source}

Real-world data were extracted from the Truven Health Analytics MarketScan ${ }^{\circledR}$ Multi-State Medicaid and Commercial insurance claim databases (with data covering the period of January 1, 2009 through December 31, 2013). These databases include inpatient medical, outpatient medical, and outpatient prescription drug information for $\sim 40$ million individuals with employer-sponsored health insurance and 28 million Medicaid beneficiaries, from 15 states across the US. The Medicaid database includes data from multiple states that are geographically diverse and also heterogeneous with respect to sociodemographics; the Commercial database includes data from all states in the US. This study was an administrative claims study and therefore is not required to have institutional review board approval or patient consent.

\section{Patient selection criteria}

Data from patients who had previous exposure to typical antipsychotics (AAs) but were newly initiating a monotherapy treatment with commonly used first-line AAs (aripiprazole, asenapine, iloperidone, lurasidone, olanzapine, paliperidone, quetiapine, risperidone, or ziprasidone) between January 1, 2010 and December 31, 2012 were identified from the Medicaid and Commercial databases. Clozapine was not included as a potential index drug because 
it is approved second-line specifically for treatment-resistant schizophrenia, as well as for reducing the risk of recurrent suicidal behavior in patients with schizophrenia or schizoaffective disorder who are judged to be at chronic risk for suicidal behavior. ${ }^{22}$ The date of AA therapy initiation was designated as the index date and patients were required to have claims for only one AA on the index date to be considered monotherapy initiators. The baseline period of the study was defined as the 12-month pre-index period and was used to evaluate each patient's pre-existing risk factors for the AE associated with the index drug.

Patients were aged between 18-64 years as of the index date and had $\geq 12$ months of continuous enrollment and pharmacy benefits before the index date (baseline period). Patients also had $\geq 1$ inpatient or outpatient medical claim with an International Classification of Diseases, 9th Revision, Clinical Modification (ICD-9-CM) diagnosis code for schizophrenia (295.xx) during the baseline period or on the date of index. Only patients with mental health and substance abuse coverage as a part of their health plan throughout the baseline period were included in this analysis.

Patients with ICD-9-CM claims for schizoaffective or schizophreniform disorder (295.4 or 295.7), and no claims for schizophrenia (295.xx), were excluded from the analysis. In addition, patients with $\geq 1$ inpatient or outpatient medical claim with an ICD-9-CM diagnosis code for dementia/ delirium (290.xx, 294.1x, 294.2x, 293.0x, 331.0x, 331.2x), during the baseline period, were excluded as this would be a potentially off-label use for currently available antipsychotics (there is a class-level bolded boxed warning for antipsychotics regarding increased mortality in elderly patients with dementia-related psychosis). ${ }^{23}$

\section{Assignment of $\mathrm{AE}$ risk}

The presence of an AE risk factor was defined as having either prior history of the particular $\mathrm{AE}$ or a risk factor for the $\mathrm{AE}$. The presence of AE risk factors associated with an AA was quantified throughout the baseline period and on the index date from administrative claims data using criteria previously described. ${ }^{16}$ Based on previously analyzed prescribing information and meta-analysis, tolerability of AAs for patient-level risk factors can be identified via administrative claims data as highlighted in Table 1. ${ }^{24-32}$ When searching claims for relevant diagnoses, claims associated with services that may be used to determine whether a patient has a given condition (eg, laboratory claims, radiology claims) were not considered. This approach was taken because such claims may have diagnoses recorded for a condition that is being ruled out, and
Table I Potential adverse events with select first-line atypical antipsychotics

\begin{tabular}{|c|c|c|c|c|c|c|c|c|c|}
\hline & $\begin{array}{l}\frac{0}{0} \\
\frac{1}{0} \\
\frac{0}{2} \\
\frac{2}{2}\end{array}$ & 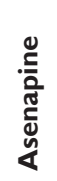 & $\begin{array}{l}\stackrel{0}{0} \\
\frac{0}{0} \\
\frac{0}{0} \\
\frac{0}{0} \\
ٍ\end{array}$ & 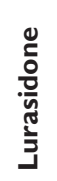 & 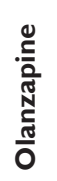 & $\begin{array}{l}\stackrel{0}{0} \\
\frac{0}{0} \\
\frac{0}{d} \\
\frac{.0}{\pi} \\
0\end{array}$ & 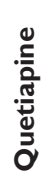 & $\begin{array}{l}\stackrel{0}{0} \\
\frac{0}{0} \\
\frac{0}{2} \\
\frac{0}{0} \\
\frac{0}{x}\end{array}$ & $\begin{array}{l}\frac{0}{2} \\
\frac{0}{0} \\
\frac{0}{y} \\
\frac{0}{n}\end{array}$ \\
\hline Akathisia & $x$ & $\mathrm{X}$ & & $x$ & $\mathrm{X}$ & $x$ & & $x$ & $x$ \\
\hline Cataracts & & & & & & & $x$ & & \\
\hline Diabetes & & & & & $\mathbf{x}$ & & $\mathbf{x}$ & $\mathbf{x}$ & \\
\hline Extrapyramidal symptoms & $\mathbf{x}$ & $\mathbf{x}$ & & $\mathbf{x}$ & $\mathbf{x}$ & $\mathbf{x}$ & & $\mathbf{x}$ & $\mathbf{x}$ \\
\hline Hyperlipidemia & & & & & $\mathbf{x}$ & & $\mathbf{x}$ & & \\
\hline Hyperprolactinemia & & & & & & $x$ & & $x$ & \\
\hline Hypothyroidism & & & & & & & $\mathbf{x}$ & & \\
\hline Obesity & & & & & $\mathbf{x}$ & & $\mathbf{x}$ & $\mathbf{x}$ & \\
\hline Orthostatic hypotension & & & $\mathbf{x}$ & & & & $\mathbf{x}$ & & \\
\hline Priapism (males only) & & & $x$ & & & $x$ & $x$ & $x$ & $\mathrm{X}$ \\
\hline QT interval prolongation & & $\mathbf{x}$ & $\mathbf{x}$ & & & $\mathbf{x}$ & $\mathbf{x}$ & & $\mathbf{x}$ \\
\hline Sedation/somnolence & & $\mathrm{x}$ & & $x$ & $x$ & & $x$ & $x$ & \\
\hline Tardive dyskinesia $^{\mathrm{a}}$ & $x$ & $x$ & $x$ & $x$ & $x$ & $x$ & $x$ & $x$ & $\mathrm{X}$ \\
\hline Transaminase elevations & & & & & & & $x$ & & \\
\hline
\end{tabular}

Notes: Adapted from Citrome et $\mathrm{al}^{16}$ and based on respective Pl. Items marked with an " $X$ " are AEs associated with that particular AA based on the PI (a specific warning for an $A E$ or as an $A E$ listed as $\geq 5 \%$ and twice the rate of placebo), and/or are generally more associated with that antipsychotic than for the other antipsychotics in the given row. AE severity was not addressed for this analysis and not all AEs have the same impact. Bold text indicates atypical antipsychotics for patient-level risk factors that can be identified via administrative claims data. ${ }^{a}$ All antipsychotics have a warning about tardive dyskinesia in product labeling; however, actual risk may differ from drug to drug and also depends on individual baseline risk factors of patients receiving these medications. Copyright $\odot$ 2014. Bentham Science Publishers. Adapted by permission of Eureka Science Ltd from Citrome L, Johnston S, Nadkarni A, Sheehan JJ, Kamat SA, Kalsekar I. Prevalence of pre-existing risk factors for adverse events associated with atypical antipsychotics among commercially insured and Medicaid insured patients newly initiating atypical antipsychotics. Curr Drug Saf. 2014;9:227-235. ${ }^{16}$

Abbreviations: AA, atypical antipsychotics; $\mathrm{AE}$, adverse event; $\mathrm{Pl}$, prescribing information.

therefore the use of such claims for identification of relevant diagnoses may introduce false-positive results.

\section{Statistical analysis}

Bivariate analyses were conducted using SAS ${ }^{\circledR}$ System Version 9 for Microsoft ${ }^{\circledR}$ (Microsoft Corporation, Redmond, WA, USA) and Windows ${ }^{\circledR}$ (SAS Institute Inc., Cary, NC, USA). Data for Medicaid-insured and Commercially insured patients were analyzed separately. Continuous variables were summarized by the mean, standard deviation (SD), minimum, median, and maximum values of the variable's distribution; categorical variables were summarized with the number and percentage of patients in each category.

\section{Assignment of patient segments and tolerable treatments}

To evaluate the unmet need of lack of sufficient treatment options available, four commonly occurring patient segments were identified through expert opinion. A nonsystematic literature search was then conducted to estimate the proportion 
of schizophrenia patients within each patient segment. The four segments were defined as follows:

1. Patients with cardiometabolic and cardiovascular comorbid conditions: Diabetes, weight gain, CVD, orthostatic hypotension, QTc prolongation.

2. Considerations related to prolactin elevation: Prolactin elevation, bone growth-related problems, sexual dysfunction, menstrual irregularities.

3. Patients' needing to avoid excessive sedation (sedation, somnolence, hypersomnia).

4. Patients who may have issues with EPS: EPS, akathisia. Tolerable treatment options for these patient segments were based on prescribing information (ie, the product label from each manufacturer) and published meta-analyses of clinical trials. Treatments were defined as not tolerable if they had a specific warning for an $\mathrm{AE}$ in the relevant patient segment or had that $\mathrm{AE}$ listed as $\geq 5 \%$ and twice the rate for placebo.

\section{Results}

From a total of 627,854 and 1,155,244 database patients (January 1, 2008 to December 31, 2013) with a schizophrenia prescription or medical claim, 15,626 (2.5\%) and 3,460 $(0.3 \%)$ patients in the Medicaid and Commercial databases, respectively, met all study criteria and were included in the study. Mean patient age was 42.9 and 43.3 years for the Medicaid and Commercial cohorts, respectively (Table 2). The patients from the Commercial database had a slightly lower Charlson Comorbidity Index compared with the patients from the Medicaid database (0.6, SD 1.2 vs 0.9, SD 1.5).

In both databases, a large proportion of patients with a known AE risk factor were treated with an AA associated with a risk factor for that $\mathrm{AE}$ prior to starting the therapy prescribed to that individual (Figure 1). A large proportion of patients with an AE risk factor for EPS (81.9\% and 82.3\% in Medicaid and Commercial databases, respectively), initiated treatment with an AA for which the criteria identified in the prescribing information showed was associated with high risk of EPS. Similar trends were found among patients from Medicaid and Commercial databases, respectively, who were diabetic $(66.9 \%$ and $61.5 \%)$, obese $(63.2 \%$ and $62.6 \%)$, and had experienced QT interval prolongation (40.9\% and $40.8 \%$ ) and were initiated on AA treatments that were associated with these AEs based on the prescribing information.

Overall, $80.4 \%$ of patients from the Medicaid database and $72.8 \%$ from the Commercial database had at least one risk factor for an AE associated with a particular AA treatment (Figure 2). Percent of patients receiving individual AAs
Table 2 Patient demographics and characteristics

\begin{tabular}{|c|c|c|}
\hline & $\begin{array}{l}\text { Medicaid } \\
(N=15,626)\end{array}$ & $\begin{array}{l}\text { Commercial } \\
(\mathrm{N}=\mathbf{3}, \mathbf{4 6 0})\end{array}$ \\
\hline Mean age, years (SD) & $42.9(12.0)$ & $43.3(14.0)$ \\
\hline \multicolumn{3}{|l|}{ Age group, years, n (\%) } \\
\hline $18-34$ & $4,258(27.2)$ & I,02I (29.5) \\
\hline $35-44$ & $3,425(21.9)$ & $560(16.2)$ \\
\hline $45-54$ & $5,096(32.6)$ & $966(27.9)$ \\
\hline $55-64$ & $2,847(\mid 8.2)$ & $913(26.3)$ \\
\hline \multicolumn{3}{|l|}{ Sex, n (\%) } \\
\hline Male & $8,443(54.0)$ & I,793 (5I.8) \\
\hline Female & $7,183(46.0)$ & $\mathrm{I}, 667(48.2)$ \\
\hline \multicolumn{3}{|l|}{ Insurance plan type, n (\%) } \\
\hline $\begin{array}{l}\text { Basic/major medical or } \\
\text { comprehensive }\end{array}$ & $10,160(65.0)$ & $345(10.0)$ \\
\hline EPO & $0(0)$ & $38(1.1)$ \\
\hline $\mathrm{HMO}$ & $935(6)$. & $728(21.0)$ \\
\hline POS & $0(0)$ & $304(8.8)$ \\
\hline PPO & $0(0)$ & $\mathrm{I}, 825$ \\
\hline POS with capitation & $4,53 \mid(29.0)$ & $22(0.6)$ \\
\hline CDHP or HDHP & $0(0)$ & $86(2.5)$ \\
\hline Other/unknown & $0(0)$ & $112(3.2)$ \\
\hline \multicolumn{3}{|l|}{ Race, n (\%) } \\
\hline White & $7,332(46.9)$ & - \\
\hline Black & $7,084(45.3)$ & - \\
\hline Hispanic & $178(I . I)$ & - \\
\hline Other & $925(5.9)$ & - \\
\hline Missing & $107(0.7)$ & - \\
\hline \multicolumn{3}{|l|}{ Geographic region, n (\%) } \\
\hline Northeast & - & $523(15.1)$ \\
\hline North Central & - & 1,086 \\
\hline South & - & $\mathrm{I}, 16 \mathrm{I}(33.6)$ \\
\hline West & - & $664(19.2)$ \\
\hline Unknown & - & $26(0.8)$ \\
\hline \multicolumn{3}{|c|}{ Deyo Charlson Comorbidity Index } \\
\hline Mean (SD) & $0.9(1.5)$ & $0.6(1.2)$ \\
\hline
\end{tabular}

Abbreviations: CDHP, consumer-driven health plan; EPO, exclusive provider organization; HDHP, health care-driven health plan; HMO, health maintenance organization; POS, point of service; PPO, preferred provider option; SD, standard deviation.

with a specific AE risk factor for that AA for the Medicaid and Commercial databases, respectively, ranged from $38.5 \%$ and $28.7 \%$ for both lurasidone and aripiprazole to $68.6 \%$ and $60.1 \%$ for olanzapine. Even in the groups with the lowest percentages (lurasidone and aripiprazole), patients received the drug despite the AE risk, suggesting an unmet need for newer treatment options with improved tolerability profiles.

For this study, four patient segments with highest unmet need for tolerable schizophrenia treatments were defined via expert opinion: patients with 1) cardiometabolic and cardiovascular comorbidities; 2) conditions related to prolactin elevation; 3) a need to avoid excessive sedation; and 4) issues with EPS. AA package inserts and meta-analyses of clinical trials were investigated to identify potential tolerable treatment options for patients in each segment (Figure 3). 


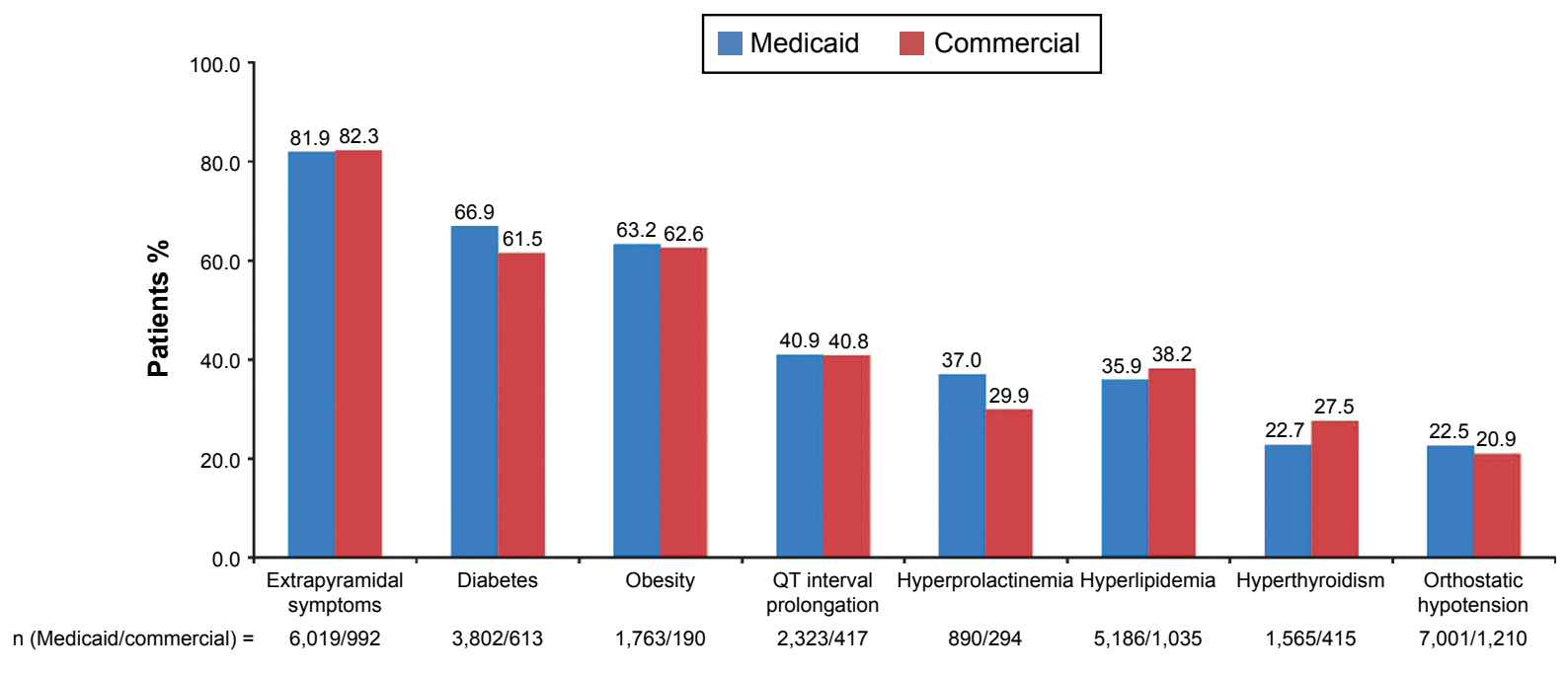

AE risk factors

Figure I Proportion of schizophrenia patients with AE risk factors at baseline who were treated with AAs associated with that AE.

Note: Percentages represent the proportion of patients with an AE risk factor who were also prescribed an $A A$ associated with that $A E$.

Abbreviations: AAs, atypical antipsychotics; AE, adverse event.

Treatment options were limited in the various patient segments by taking into consideration the individual conditions for each segment, and treatment options were reduced even further for patients in multiple commonly co-occurring segments. Figure 3 illustrates the lack of treatment options for patients in single or in multiple commonly co-occurring segments. As an example, patients with a need for sedation avoidance have four tolerable treatment options (aripiprazole, iloperidone, paliperidone, and ziprasidone), and patients with a risk factor for EPS or akathisia have two tolerable treatment options (iloperidone and quetiapine). When a patient presents characteristics of both of these segments (combining segments 3 and 4), treatment options are reduced to just iloperidone.

\section{Discussion}

There are a number of antipsychotic agents currently on the market ${ }^{6}$ and these agents are substantially different from each other in many ways, including individual efficacy and side-effect profiles. ${ }^{15,52}$ Additionally, although antipsychotics can be separated into typical (first-generation) and atypical (second-generation) classes, there are considerable differences between individual agents and overlap between the two groups in terms of adverse effects.$^{53}$ However, recent trends in health plan formulary access indicate many firstgeneration and generic second-generation AAs are preferred and are used interchangeably in many health plans. The results presented in the current study illustrate that real-world AA treatments are often administered to inappropriate patient

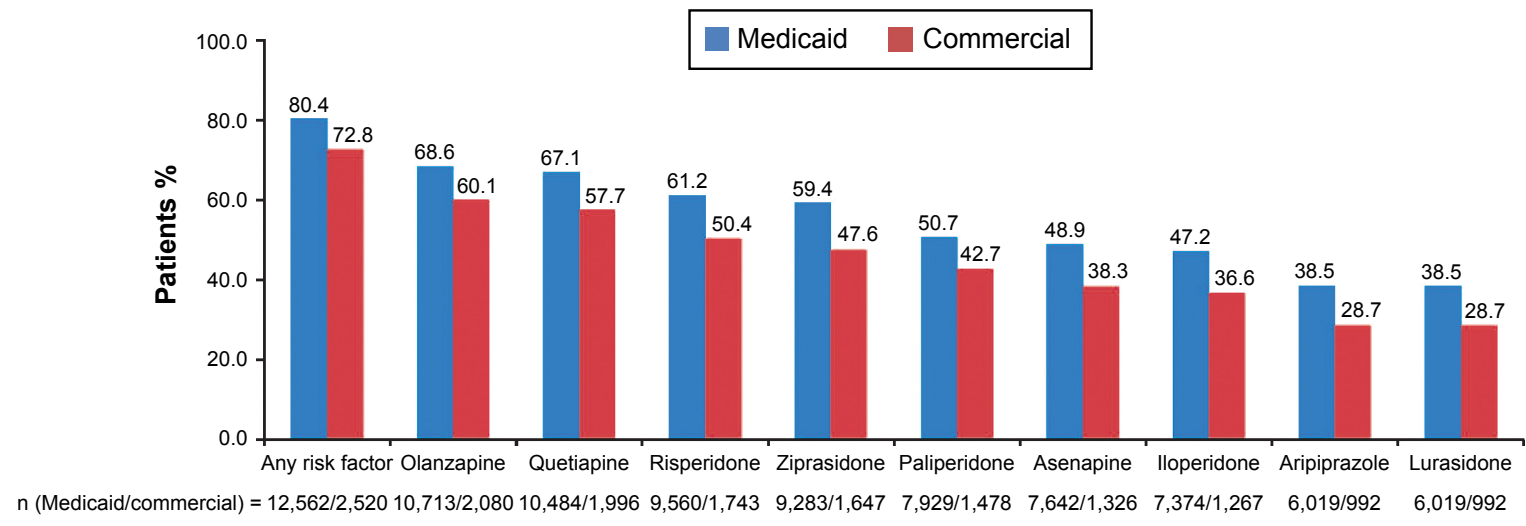

AA risk factors

Figure 2 Prevalence of AE risk factors for AAs in the Medicaid and Commercial populations.

Note: Percentages represent the proportion of patients with any AE risk factor associated with the AA they were prescribed.

Abbreviations: AA, atypical antipsychotic; $A E$, adverse event. 


\begin{tabular}{|c|c|c|}
\hline $\begin{array}{l}\text { Individual patient } \\
\text { segments having: }\end{array}$ & $\begin{array}{l}\text { Proportion of patients } \\
\text { with schizophrenia } \\
\text { within a segment }\end{array}$ & Tolerable treatment options \\
\hline $\begin{array}{l}\text { Segment } 1 \\
\text { Diabetes, CVD, overweight, } \\
\text { orthostatic hypotension, } \\
\text { QTC prolongation }\end{array}$ & $\begin{array}{l}22 \% \text { diabetes }^{3,33,34} \\
13 \% \text { CVD }^{34} \\
23 \%-53 \% \text { overweight } 33,35,36 \\
18 \%-40 \% \text { orthostatic hypotension } \text { hy }^{3,33} \\
3 \%-5 \% \text { QTc prolongation } \\
37,38\end{array}$ & $\begin{array}{l}\text { Aripiprazole, asenapine, } \\
\text { lurasidone, paliperidone } \\
4 \text { options }\end{array}$ \\
\hline $\begin{array}{l}\text { Segment } 2 \\
\text { Considerations related } \\
\text { to prolactin elevation }\end{array}$ & $\begin{array}{l}31 \%-39 \% \text { increased prolactin }{ }^{39-41} \\
52 \% \text { osteoporosis, } 40 \% \text { osteopenia }^{42} \\
30 \%-80 \% \text { sexual dysfunction } \\
18 \%, 43,44 \\
\text { menstrual irregularities }{ }^{43}\end{array}$ & $\begin{array}{l}\text { Aripiprazole, asenapine, } \\
\text { iloperidone, lurasidone, } \\
\text { olanzapine, quetiapine, } \\
\text { ziprasidone } \\
7 \text { options }\end{array}$ \\
\hline $\begin{array}{l}\text { Segment } 3 \\
\text { Need to avoid } \\
\text { excessive sedation }\end{array}$ & $\begin{array}{l}5 \%-25 \% \text { in college or other school }{ }^{35,45,46} \\
20 \%-55 \% \text { with part or full-time jobs }{ }^{45,47,48} \\
60 \% \text { fatigue, } 47 \% \text { sedation } \\
36,49\end{array}$ & $\begin{array}{l}\text { Aripiprazole, iloperidone, } \\
\text { paliperidone, ziprasidone } \\
4 \text { options }\end{array}$ \\
\hline $\begin{array}{l}\text { Segment } 4 \\
\text { EPS or akathisia }\end{array}$ & $\begin{array}{l}34 \%-58 \%-\text { EPS }^{36,50} \\
7 \%-35 \% \text { - akathisia } \\
50,51\end{array}$ & $\begin{array}{l}\text { lloperidone, quetiapine } \\
2 \text { options }\end{array}$ \\
\hline
\end{tabular}

\begin{tabular}{l} 
Patients with characteristics from multiple segments \\
\hline $\begin{array}{l}\text { Diabetes, CVD, } \\
\text { overweight, } \\
\text { orthostatic hypotension, } 1 \text { and } 2\end{array}$ \\
$\begin{array}{l}\text { QTc prolongation } \\
\text { to prolactin elevation }\end{array}$ \\
\hline
\end{tabular}

Tolerable treatment options

\begin{tabular}{l|l|l|}
$\begin{array}{l}\text { Need to avoid } \\
\text { excessive sedation }\end{array}$ & 3 and 2 & $\begin{array}{l}\text { Considerations related } \\
\text { to prolactin elevation }\end{array}$ \\
\hline
\end{tabular}

Aripiprazole, asenapine, lurasidone

3 options combining segments 1 and 2

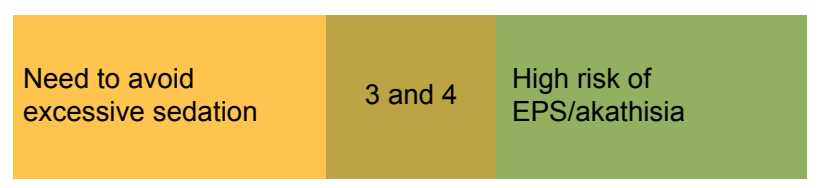

Aripiprazole, iloperidone, ziprasidone 3 options combining segments 3 and 2

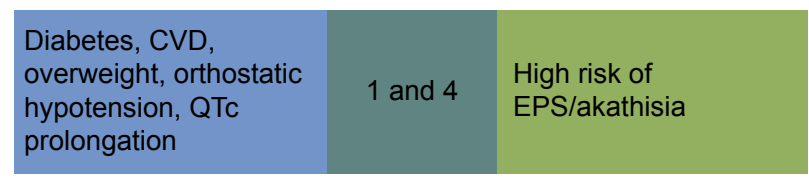

lloperidone 1 option combining segments 3 and 4

Figure 3 Available treatment options for patients with prior exposure to AAs. ${ }^{a}$

Notes: aApproved treatment options include aripiprazole, asenapine, iloperidone, lurasidone, paliperidone, olanzapine, quetiapine, risperidone, ziprasidone and are based on prescribing information review of AAs; a specific warning for an $A E$ in the patient segment or an $A E$ listed as $\geq 5 \%$ and twice the rate of placebo resulted in elimination of the $\mathrm{AA}$ as tolerable.

Abbreviations: AA, atypical antipsychotic; AE, adverse event; CVD, cardiovascular disease; EPS, extrapyramidal symptoms; QTc, corrected Q-T interval.

groups, and that physicians may run out of current tolerable treatment options for individual patients despite the fact that there are many AAs available for schizophrenia treatment.

According to the presented results, patients with schizophrenia may not be getting the most appropriate treatment in consideration of their individual AE risk factors. When examining the results from both databases, Medicaid-insured and Commercially insured, a large proportion of patients at risk for an $\mathrm{AE}$ are receiving AAs associated with that particular risk factor. Likewise, large proportions of patients 
$(30 \%-70 \%)$ in the study had risk factors for at least one $\mathrm{AE}$ associated with their prescribed AA, suggesting an unmet need for newer and more tolerable treatment options. In addition, there is approximately a $10 \%$ difference between Commercial and Medicaid patients being placed on drugs associated with existing risk factors. It is possible that within the bounds of Medicaid-insured care, there are fewer resources available leading to fewer treatment choices and ultimately resulting in more inappropriate prescribing of these drugs.

Cardiometabolic disease is of particular concern among patients with schizophrenia. These patients have an increased risk of metabolic syndrome compared with the general population, and this risk is increased by many antipsychotic medications. ${ }^{33,54-56}$ Here we show, both via insurance claims data and literature sources, that the prevalence of metabolic disease comorbidities is high in these patients. Adding to the problem is the lack of physician monitoring of commonly co-occurring medical conditions, including diabetes, obesity, and CVD. A recent study found that, while community mental health centers generally conform to the 2003 Patient Outcomes Research Team treatment recommendations, conformance with Mount Sinai Conference recommendations for monitoring somatic health was followed less than $50 \%$ of the time. ${ }^{18}$

Evaluation of AA treatment product labeling and published meta-analyses illustrates the restricted options of treatment for individual patient segments. We have focused on four common schizophrenia patient segments in this study. The first segment includes cardiometabolic and cardiovascular comorbidities of diabetes, weight gain, orthostatic hypotension and QTc prolongation, for which treatment options of iloperidone, olanzapine, quetiapine, risperidone, and ziprasidone have been eliminated based on the AEs risk of these drugs related to these comorbidities. ${ }^{57-59}$ In the second patient segment, considerations related to prolactin elevation, paliperidone, and risperidone were eliminated as treatment choices based on their association with increasing prolactin. ${ }^{60-63}$ For the third segment, needing to avoid excessive sedation, asenapine, lurasidone, olanzapine, quetiapine, and risperidone were eliminated ${ }^{64}$ and all antipsychotics except iloperidone and quetiapine were eliminated for patients in segment four, issues with EPS or akathisia, because of the restlessness or EPS side effects of these drugs. ${ }^{65,66}$ In this analysis, AE severity was not addressed. Individual impact of AEs is unclear and can also be dependent on patient or clinician perception. When these patient segments are combined (as is the case for many patients with schizophrenia), treatment options are substantially reduced, stressing the importance of having additional treatment options for patients with various characteristics. As shown in Figure 3, tolerable treatment options for patients with cardiometabolic and cardiovascular comorbidities including diabetes, weight gain, CVD, orthostatic hypotension, and QT prolongation is limited to a choice of four AAs. When these patients also have other risk factors, for example, prolactin elevation or EPS, those treatment options decrease further to three and zero options, respectively.

Given that antipsychotics have complex pharmacodynamic profiles, the specific reason for AE risk for these drugs is complex. ${ }^{67}$ Pharmacologic profiles of some agents have been theorized to explain increased risk for some of the adverse effects encountered. For example, iloperidone's high affinity to $\alpha 1$-adrenergic receptors, and functional activity as an antagonist, may explain why iloperidone is associated with orthostatic hypotension if not carefully titrated. ${ }^{68}$ In contrast, $\alpha 1$-antagonism has also been proffered as a mechanism that can protect against EPS. ${ }^{69}$ Other receptor binding affinities that may be associated with adverse effects include: muscarinic M1 cholinergic antagonism, interfering with cognition and histamine $\mathrm{H} 1$ receptor antagonism, causing sedation as well as weight gain. It has been proposed that histamine $\mathrm{H} 1$ receptor blockade can be a predictor of weight gain. ${ }^{70}$ Clinical trials are needed to systematically determine the effects of specific binding profiles in patients with schizophrenia. Moreover, there is individual variability between patients regarding AA effects on body weight. A more complete discussion of antipsychotic mechanism of action in relation to side-effect liability is available elsewhere. ${ }^{71}$

The results presented here need to be viewed in light of limitations involved in this type of study. The data used for Table 1 to illustrate AEs associated with specific antipsychotics were based on prescribing information for the specific drugs and were not compared quantitatively. In addition, severity of individual AEs was not taken into account for this table as well as the administrative claims data in Figures 1 and 2, and so it is not clear if the AEs have equivalent patient impact. This fact could lead to differential interpretation of the data because AEs may be viewed differently by individual patients and by physicians. Administrative claims data may have suboptimal sensitivity for identification of certain underdiagnosed or undercoded risk factors for AAassociated AEs (eg, obesity), leading to underrepresentation. Additionally, the prevalence of AE risk factors may be underestimated in cases where patients may have a risk 
factor, but no administrative claims-based evidence was present within the year prior to initiation.

Furthermore, because the databases used for this study do not contain laboratory results, certain conditions for which laboratory data would be ideal (eg, hyperlipidemia) required ascertainment using diagnosis coding, which may contain inaccuracies. Drug samples provided to the patient by their doctor, and prescriptions filled in situations where the patients do not make use of their prescription drug coverage were not captured in the MarketScan pharmacy claims databases.

Nonetheless, the results of this study indicate the very real possibility that physicians may run out of tolerable treatment options for individual patients, despite the appearance that there are many AAs available for schizophrenia treatment. This suggests a need for additional treatment options to select from for patients with schizophrenia.

\section{Author contribution}

LC, AE, CF, RD, SNL, SO, HK, SJ, AG-D, and SAK contributed to the research and design of this study. LC, AE, CF, RD, SO, HK, SJ, AG-D, PR, and SAK contributed to analysis and interpretation of data. Supervisory contributions were made by $\mathrm{SO}, \mathrm{SJ}$, and $\mathrm{SAK}$; contributions related to administrative, technical, or material support were made by SNL. All authors contributed to the writing, review, and revision of the manuscript. All authors gave final approval of the manuscript prior to publication and agree to be responsible for all aspects of the work.

\section{Disclosure}

This study was sponsored by Otsuka America Pharmaceutical, Inc., Princeton, NJ, USA, Otsuka Pharmaceutical Development and Commercialization, Inc., Princeton, NJ, USA, and Lundbeck LLC, Copenhagen, Denmark. Medical writing and editorial support for the preparation of this manuscript was provided by Scientific Connexions, Lyndhurst, NJ, USA, an Ashfield Company, part of UDG Healthcare plc, funded by Otsuka America Pharmaceutical, Inc., Princeton, NJ, USA, and Lundbeck LLC, Copenhagen, Denmark.

For the past 36 months, LC has been engaged in collaborative research with or has received consulting or speaking fees, from: Alexza, Alkermes, Allergan, AstraZeneca, Avanir, Boehringer Ingelheim, Bristol-Myers Squibb, Eli Lilly, Forum, Genentech, Janssen, Jazz, Lundbeck, Merck, Medivation, Mylan, Novartis, Noven, Otsuka, Pfizer, Reckitt Benckiser, Reviva, Shire, Sunovion, Takeda, Teva, and Valeant, and owns a small number of shares of common stock in Bristol-Myers Squibb, Eli Lilly, J \& J, Merck, and
Pfizer. AE and CF are employees of Lundbeck and AG-D is an employee of Lundbeck SAS. RD, SNL, SO, HK, SAK, and PR are employees of Otsuka America Pharmaceutical, Inc. SJ is an employee of Truven Health Analytics, which has received funds from Otsuka America Pharmaceutical, Inc. in connection with the conduction of this study. The authors report no other conflicts of interest in this work.

\section{References}

1. National Institute of Mental Health. Numbers count: mental disorders in America. Bethesda, MD: National Institute of Mental Health; 2013. Available from: http://www.nimh.nih.gov/health/publications/the-numbers-count-mental-disorders-in-america/index.shtml\#Schizophrenia. Accessed March 6, 2015.

2. US Census Bureau. Age and sex composition: 2010 (C2010BR-03). Washington, DC: US Census Bureau; 2011. Available from: http://www. census.gov/prod/cen2010/briefs/c2010br-03.pdf. Accessed March 6, 2015.

3. Schoepf D, Uppal H, Potluri R, Heun R. Physical comorbidity and its relevance on mortality in schizophrenia: a naturalistic 12-year follow-up in general hospital admissions. Eur Arch Psychiatry Clin Neurosci. 2014;264:3-28.

4. Emsley R, Chiliza B, Asmal L, Harvey BH. The nature of relapse in schizophrenia. BMC Psychiatry. 2013;13:50.

5. Muench J, Hamer AM. Adverse effects of antipsychotic medications. Am Fam Physician. 2010;81:617-622.

6. Bruijnzeel D, Suryadevara U, Tandon R. Antipsychotic treatment of schizophrenia: an update. Asian J Psychiatr. 2014;11:3-7.

7. Cha DS, McIntyre RS. Treatment-emergent adverse events associated with atypical antipsychotics. Expert Opin Pharmacother. 2012;13: $1587-1598$.

8. Basu A, Meltzer HY. Tying comparative effectiveness information to decision-making and the future of comparative effectiveness research designs: the case for antipsychotic drugs. J Comp Eff Res. 2012;1(2): 171-180.

9. Hermes ED, Sernyak M, Rosenheck R. Impact of a program encouraging the use of generic antipsychotics. Am J Manag Care. 2012;18(8): 307-314.

10. Smith KJ, Baik SH, Reynolds CF, Rollman BL, Zhang Y. Costeffectiveness of Medicare drug plans in schizophrenia and bipolar disorder. Am J Manag Care. 2013;19(2):55-63.

11. Marder SR, Essock SM, Miller AL, et al. Physical health monitoring of patients with schizophrenia. Am J Psychiatry. 2004;161:1334-1349.

12. Lehman AF, Lieberman JA, Dixon LB. Practice guideline for the treatment of patients with schizophrenia, second edition. Am J Psychiatry. 2004;161:1-56.

13. American Diabetes Association, American Psychiatric Association, American Association of Clinical Endocrinologists, North American Association for the Study of Obesity. Consensus development conference on antipsychotic drugs and obesity and diabetes. Diabetes Care. 2004;27:596-601.

14. Meyer JM. Antipsychotics and metabolics in the post-CATIE era. Curr Top Behav Neurosci. 2010;4:23-42.

15. Leucht S, Cipriani L, Spineli L, et al. Comparative efficacy and tolerability of 15 antipsychotic drugs in schizophrenia: a multiple-treatments meta-analysis. Lancet. 2013;382:951-962.

16. Citrome L, Johnston S, Nadkarni A, Sheehan JJ, Kamat SA, Kalsekar I. Prevalence of pre-existing risk factors for adverse events associated with atypical antipsychotics among commercially insured and Medicaid insured patients newly initiating atypical antipsychotics. Curr Drug Saf. 2014;9:227-235.

17. Kennedy WK, Jann MW, Kutscher EC. Clinically significant drug interactions with atypical antipsychotics. CNS Drugs. 2013;27: 1021-1048. 
18. Keller WR, Fischer BA, McMahon R, et al. Community adherence to schizophrenia treatment and safety monitoring guidelines. J Nerv Ment Dis. 2014;202:6-12.

19. Falkai P, Wobrock T, Lieberman J, et al. World Federation of Societies of Biological Psychiatry (WFSBP) guidelines for biological treatment of schizophrenia, Part 1: acute treatment of schizophrenia. World J Biol Psychiatry. 2005;6(3):132-191.

20. Gardner KN, Bostwick JR. Antipsychotic treatment response in schizophrenia. Am J Health Syst Pharm. 2012;69:1872-1879.

21. Targum SD, Pestreich L, Reksoprodjo P, Pereira H, Guindon C, Hochfeld M. A global measure to assess switching antipsychotic medications in the treatment of schizophrenia. Hum Psychopharmacol.2012; $27: 455-463$.

22. Novartis Pharmaceuticals Corp. Clozaril (clozapine). Available from: https://www.pharma.us.novartis.com/product/pi/pdf/Clozaril.pdf. Accessed May 11, 2015.

23. Citrome L, Nasrallah HA. On-label on the table: what the package insert informs us about the tolerability profile of oral atypical antipsychotics, and what it does not. Expert Opin Pharmacother. 2012;13(11): 1599-1613.

24. AstraZeneca Pharmaceuticals LP. Seroquel (quetiapine). Available from: http://www1.astrazeneca-us.com/pi/Seroquel.pdf. Accessed March 6, 2015

25. Eli Lilly and Company. Zyprexa (olanzapine). Available from: http:// pi.lilly.com/us/zyprexa-pi.pdf. Accessed March 6, 2015

26. Forest Pharmaceutical Inc. Saphris (asenapine). Available from: http://pi.actavis.com/data_stream.asp?product_group $=1908 \&$ p= pi\&language $=$ E. Accessed March 6, 2015

27. Janssen Pharmaceuticals, Inc. Invega (paliperidone). Available from http://www.janssencns.com/sites/default/files/pdf/invega/invega.pdf. Accessed March 17, 2015.

28. Janssen Pharmaceuticals, Inc. Risperdal (risperidone). Available from: http://www.janssenpharmaceuticalsinc.com/assets/risperdal.pdf. Accessed March 6, 2015.

29. Novartis Pharmaceuticals Corp. Fanapt (iloperidone). Available from: http://www.fanapt.com/product/pi/pdf/fanapt.pdf. Accessed March 10, 2015.

30. Otsuka Pharmaceutical Co., Ltd. Abilify (aripiprazole). Available from: http://www.otsuka-us.com/Documents/Abilify.PI.pdf. Accessed March 6, 2015.

31. Pfizer, Inc. Geodon (ziprasidone). Available from: http://labeling.pfizer. com/ShowLabeling.aspx?id=584. Accessed March 6, 2015.

32. Sunovion Pharmaceuticals Inc. Latuda (lurasidone hydrochloride) Available from: http://www.latuda.com/LatudaPrescribingInformation. pdf. Accessed March 10, 2015.

33. Mitchell AJ, Vancampfort D, De Herdt A, Yu W, De Hert M. Is the prevalence of metabolic syndrome and metabolic abnormalities increased in early schizophrenia? A comparative meta-analysis of first-episode untreated and treated patients. Schizophr Bull. 2013;39:295-305.

34. Viertio S, Tuulio-Henriksson A, Perala J, et al. Activities of daily living, social functioning and their determinants in persons with psychotic disorder. Eur Psychiatry. 2012;27:409-415.

35. Papageorgiou G, Canas F, Zink M, Rossi A. Country differences in patient characteristics and treatment in schizophrenia: data from a physician-based survey in Europe. Eur Psychiatry. 2011;26:17-28.

36. Millier A, Amri I, Boyer L, Auquier P, Toumi M. Utility decrements associated with side effects in schizophrenia. J Med Econ. 2014;17:853-861.

37. Ozeki Y, Fujii K, Kurimoto, et al. QTc prolongation and antipsychotic medications in a sample of 1017 patients with schizophrenia. Prog Neuropsychopharmacol Biol Psychiatry. 2010;34:401-405.

38. Yang FD, Wang XQ, Liu XP, et al. Sex difference in QTc prolongation in chronic institutionalized patients with schizophrenia on long-term treatment with typical and atypical antipsychotics. Psychopharmacology (Berl). 2011;216:9-16.

39. Riechler-Rossler A, Rybakowski JK, Pflueger MO, et al. Hyperprolactemia in antipsychotic-naïve patients with first-episode psychosis. Psychol Med. 2013;43:2571-2582.
40. Bushe C, Shaw M. Prevalence of hyperprolactinaemia in a naturalistic cohort of schizophrenia and bipolar outpatients during treatment with typical and atypical antipsychotics. J Psychopharmacol. 2007;21: 768-773.

41. Kinon BJ, Liu-Seifert H, Stauffer VL, Jacob J. Bone loss associated with hyperprolactinemia in patients with schizophrenia. Clin Schiz Related Psychoses. 2013;7(3):115-123.

42. Stubbs B, De Hert M, Sepehry AA, et al. A meta-analysis of prevalence estimates and moderators of low bone mass in people with schizophrenia. Acta Psychiatr Scand. 2014;130(6):470-486.

43. Karthik MS, Kulhara P, Chakrabarti S. Attitude towards secondgeneration antipsychotics among patients with schizophrenia and their relatives. Hum Psychopharmacol. 2013;28:457-465.

44. Baggaley M. Sexual dysfunction in schizophrenia: focus on recent evidence. Hum Psychopharmacol. 2008;23:201-209.

45. Abdel-Baki A, Letourneau G, Morin C, Ng A. Resumption of work or studies after first episode psychosis: the impact of vocational case management. Early Interv Psychiatry. 2013;7:391-398.

46. Meltzer HY. Outcome in schizophrenia: beyond symptom reduction. J Clin Psychiatry. 1999;60:3.

47. Vargas G, Strassnig M, Sabbag S, et al. The course of vocational functioning in patients with schizophrenia: re-examining social drift. Schizophr Res Cogn. 2014;1:41-46.

48. Haro JM, Novick D, Perrin E, Bertsch J, Knapp M. Symptomatic remission and patient quality of life in an observational study of schizophrenia: is there a relationship? Psychiatry Res. 2014;220:163-169.

49. Waters F, Naik N, Rock D. Sleep, fatigue, and functional health in psychotic patients. Schizophr Res Treatment. 2013;2013:425826.

50. Peralta V, de Jalon EG, Campos MS, Cuesta MJ. Phenomenological differences between spontaneous and drug-related extrapyramidal syndromes in patients with schizophrenia-spectrum disorders. J Clin Psychopharm. 2013;33:438-440.

51. Kane JM, Fleischhacker WW, Hansen L, Perlis R, Pikalov A 3rd, Assunção-Talbott S. Akathisia: an updated review focusing on secondgeneration antipsychotics. J Clin Psychiatry. 2009;70:627-643.

52. Citrome L. A review of the pharmacology, efficacy and tolerability of recently approved and upcoming oral antipsychotics: an evidence-based medicine approach. CNS Drugs. 2013;27(11):879-911.

53. Volavka J, Citrome L. Oral antipsychotics for the treatment of schizophrenia: heterogeneity in efficacy and tolerability should drive decisionmaking. Expert Opin Pharmacother. 2009;10(12):1917-1928.

54. Citrome L, Kalsekar I, Baker RA, Hebden T. A review of real-world data on the effects of aripiprazole on weight and metabolic outcomes in adults. Curr Med Res Opin. 2014;30:1629-1641.

55. Lasic D, Bevanda M, Bosnjak N, Uglešić B, Glavina T, Franić T. Metabolic syndrome and inflammation markers in patients with schizophrenia and recurrent depressive disorder. Psychiatr Danub. 2014;26: 214-219.

56. Kucerova J, Babinska Z, Horska, K, Kotolova H. The common pathophysiology underlying the metabolic syndrome, schizophrenia, and depression: a review. Biomed Pap Med Fac Univ Palacky Olomourc Czech Repub. 2015;159(2):208-214.

57. Rojo LE, Gaspar PA, Silva H, et al. Metabolic syndrome and obesity among users of second generation antipsychotics: a global challenge for modern psychopharmacology. Pharmacol Res. Epub 2015 Jul 25.

58. Leung JY, Barr AM, Procyshyn RM, Honer WG, Pang CC. Cardiovascular side-effects of antipsychotic drugs: the role of the autonomic nervous system. Pharmacol Ther. 2012;135(2):113-122.

59. Hasnain M, Vieweg WV. QTc interval prolongation and torsade de pointes associated with second-generation antipsychotics and antidepressants: a comprehensive review. CNS Drugs. 2014;28(10):887-920.

60. De Hert M, Detraux J, Peuskens J. Second-generation and newly approved antipsychotics, serum prolactin levels and sexual dysfunctions: a critical literature review. Expert Opin Drug Saf. 2014;13(5):605-624.

61. Peuskens J, Pani L, Detraux J, De Hert M. The effects of novel and newly approved antipsychotics on serum prolactin levels: a comprehensive review. CNS Drugs. 2014;28(5):421-453. 
62. Bargiota SI, Bonotis KS, Messinis IE, Angelopoulos NV. The effects of antipsychotics on prolactin levels and women's menstruation. Schizophr Res Treatment. 2013;2013:502697.

63. Just MJ. The influence of atypical antipsychotic drugs on sexual function. Neuropsychiatr Dis Treat. 2015;11:1655-1661.

64. Gao K, Ganocy SJ, Gajwani P, Muzina DJ, Kemp DE, Calabrese JR. A review of sensitivity and tolerability of antipsychotics in patients with bipolar disorder or schizophrenia: focus on somnolence. $J$ Clin Psychiatry. 2008;69(2):302-309.

65. Bratti IM, Kane JM, Marder SR. Chronic restlessness with antipsychotics. Am J Psychiatry. 2007;164(11):1648-1654.

66. Peluso MJ, Lewis SW, Barnes TR, Jones PB. Extrapyramidal motor side-effects of first- and second-generation antipsychotic drugs. Br J Psychiatry. 2012;200(5):387-392.

67. Shayegan DK, Stahl SM. Atypical antipsychotics: matching receptor profile to individual patient's clinical profile. CNS Spectr. 2004;9 (10 Suppl 11):6-14.
68. Dargani NV, Malhotra AK. Safety profile of iloperidone in the treatment of schizophrenia. Expert Opin Drug Saf. 2014;13(2):241-246.

69. Stahl SM. Role of $\alpha 1$ adrenergic antagonism in the mechanism of action of iloperidone: reducing extrapyramidal symptoms. CNS Spectr. 2013;18(6):285-288.

70. Matsui-Sakata A, Ohtani H, Sawada Y. Receptor occupancy-based analysis of the contributions of various receptors to antipsychoticsinduced weight gain and diabetes mellitus. Drug Metab Pharmacokinet. 2005;20(5):368-378.

71. Stahl SM. Stahl's Essential Psychopharmacology: Neuroscientific Basis and Practical Applications. 4th ed. Cambridge: Cambridge University Press; 2013.

\section{Publish your work in this journal}

Neuropsychiatric Disease and Treatment is an international, peerreviewed journal of clinical therapeutics and pharmacology focusing on concise rapid reporting of clinical or pre-clinical studies on a range of neuropsychiatric and neurological disorders. This journal is indexed on PubMed Central, the 'PsycINFO' database and CAS, and is the official journal of The International Neuropsychiatric Association (INA). The manuscript management system is completely online and includes a very quick and fair peer-review system, which is all easy to use. Visit http://www.dovepress.com/testimonials.php to read real quotes from published authors.

Submit your manuscript here: http://www.dovepress.com/neuropsychiatric-disease-and-treatment-journal 